\title{
NOTES DE RECERCA
}

Parejas mixtas residentes fuera de España: relaciones de género, dinámicas sociales y conexiones transnacionales ............. 239 Jordi Roca Girona

Movilidad y vida cotidiana en Cataluña: etno-geografía de los espacios y tiempos metropolitanos . . . . . . . . . . . . . . . . . . . . . . 243 Joan Josep Pujadas

Pràctiques locals i discursos globals en la reproducció de les comunitats rurals. Desenvolupament rural, agroecologia i sobirania alimentària . 248 Montserrat Soronellas Masdeu

“Encounters and Engagements": el primer congrés mundial d'antropologia mèdica, organitzat a la URV al juny del 2013 . . . . . . . . . . . . . . . 252 Oriol Romaní, Josep M. Comelles

De gladiadores y antropólog@s. Breve reseña sobre XIII Congreso de Antropología "Periferias, fronteras y diálogos" . . . . . . . . . . . . . . . . . 255 Natalia Alonso Rey

Los congresos de antropología de la FAAEEः una breve reflexión . . . . . .260 Joan Prat i Carós 



\section{Parejas mixtas residentes fuera de España‡ relaciones de género, dinámicas sociales y conexiones transnacionales [extramixt] [CSO2012-33565]}

Jordi Roca Girona ${ }^{1}$

El proyecto es continuación de dos proyectos anteriores en que abordamos, de forma pionera en España, la realidad de las parejas, uniones o matrimonios mixtos o binacionales. Entendemos por tales las uniones sentimentales estables formadas por un cónyuge español y otro extranjero surgidas en España a lo largo de la década de 1990 y cuyo número fue creciendo de forma importante hasta finales de la última década, en que llegaron a representar más del 15\% del total de matrimonios celebrados en España.

En el primer proyecto - "Amor importado, migrantes por amor: la constitución de parejas entre españoles y mujeres de América Latina y de Europa del Este en el marco de la transformación actual del sistema de género en España", Plan Nacional I+D+i (2004-2007), Instituto de la Mujer (exp. núm. 47/05) -, nos centramos en las parejas formadas por hombres españoles y mujeres extranjeras -el tipo más numeroso de pareja mixta en España, que supone cerca de las dos terceras partes del total $-\mathrm{y}$ focalizamos la atención en las motivaciones expresadas por los y las protagonistas de estas uniones para llevar a cabo un enlace de este tipo, así como en los procesos de búsqueda de pareja y de formalización de esta. En el segundo proyecto - "Amores transnacionales: constitución y desarrollo de parejas mixtas en España”, Plan Nacional de I+D+i (2008-2011) - , dirigimos la atención hacia las uniones compuestas por mujeres españolas y hombres extranjeros y profundizamos en las cuestiones relativas a la vida en común de las parejas mixtas españolas - división del trabajo entre los miembros de la pareja, educación de los hijos, relaciones con las familias de orientación, etc.-.

1 Investigador principal. Forman parte del grupo de investigación las siguientes personas: Verónica Anzil, Ana Urmeneta, Roxana Yzusqui, Cristina García, Maija Djurdjevic, Lídia Martínez, María Badet, Yvonne Riaño, Beatriz Padilla, Begonya Enguix y Ana Alcázar. 
En ambos casos dedicamos especial atención a las transformaciones de género que estas uniones implicaban para sus protagonistas, dado que ello constituía una de nuestras principales hipótesis de partida, que los datos obtenidos en las investigaciones citadas vinieron a corroborar. En este sentido, y de forma esquemática, podemos afirmar que, en buena medida, las uniones mixtas entre hombres españoles y mujeres extranjeras, cuando estas proceden de países con fuertes estructuras patriarcales y pertenecen a clases populares, acostumbran a suponer una mejora, en términos de igualdad, en las relaciones de género de estas mujeres. Por el contrario, cuando la pareja la conforman una mujer española y un hombre extranjero de clase media o baja de alguno de los principales países de procedencia de los cónyuges masculinos de estas uniones - Marruecos, Argentina, Colombia y República Dominicana, principalmente-, en general todo parece indicar que la mujer española entra en un proceso de retradicionalización más o menos acusado. Como se puede observar, pues, las relaciones de género resultantes de una unión mixta, siempre sujetas a continuos procesos de negociación, parecen estar relacionadas con distintas variables que se combinan de forma diversa, entre las cuales destacan sobre todo la nacionalidad, la clase social y el género. Así, resulte muy pertinente y relevante situar el abordaje de estas parejas que ya llevamos media década estudiando en algunas unidades de observación distintas de la que hasta ahora nos ha servido de base; es decir, recoger y evaluar la experiencia de uniones mixtas de la misma composición que las que hemos estado siguiendo en los últimos años pero residentes en contextos territoriales distintos del español. Lo que nos interesa, en suma, es ver cómo el cambio en una de las variables señaladas, en este caso la localización física - un país distinto, con estructuras de género distintas-, interviene en los procesos de definición del género y de negociación de las relaciones de género.

El proyecto actual, pues, en la línea de los anteriores, tiene como objeto abordar las parejas mixtas heterosexuales formadas por un miembro español y otro extranjero - uniones de hombres españoles con mujeres extranjeras y de mujeres españolas con hombres extranjeros - que residan fuera de España. Vamos a distinguir tres tipos de pareja: 1) aquella que desde el inicio reside en el país del cónyuge extranjero; 2) aquella que inicialmente se establece en España y con posterioridad decide emigrar al país de origen del cónyuge extranjero; y 3) aquella en la que se suceden períodos de residencia alterna en cada uno de los países de los cónyuges. El objetivo es averiguar si las expectativas, las 
relaciones de género y los procesos de construcción identitaria de estas parejas presentan diferencias o similitudes respecto a las parejas de su misma condición residentes en España, o se han transformado en el caso de parejas que han pasado de vivir aquí a hacerlo en el país del cónyuge extranjero, así como profundizar en los motivos y las razones presentes en la decisión de establecer la residencia fuera de España, ya sea de forma temporal o definitiva. La investigación resulta especialmente relevante en el contexto actual, puesto que la crisis económica ha empezado a provocar en nuestro país procesos de emigración de personas entre las cuales las parejas mixtas constituyen una realidad a la vez muy presente y diferenciada.

La literatura existente sobre uniones mixtas se integra en el creciente interés científico sobre cómo las relaciones sociales se han tornado cada vez más dispersas geográficamente, impersonales y mediatizadas por amplios procesos político-económicos o capitalistas, así como en la atención académica cada vez mayor a la intensificación y compleja interconectividad de los procesos locales y globales. Más específicamente, se constata un predominio de trabajos que se centran en los principales itinerarios que recogen los flujos de cónyuges y parejas, así como la dirección y el sentido de estos. La búsqueda global de cónyuge, en este sentido, dibuja unas rutas que van de los países ricos del occidente europeo, Norteamérica y Asia-Pacífico a regiones del Caribe, Latinoamérica, el este de Europa y el sudeste asiático.

También contamos con trabajos de carácter más general que abordan el fenómeno desde diversas perspectivas, describiendo los diversos patrones de género vinculados a la movilidad marital en un contexto global, mostrando a mujeres y hombres que toman la iniciativa, que realizan elecciones y que devienen agentes activos, apuntando las motivaciones y razones para la salida, los nuevos patrones de movilidad de personas de las distintas clases sociales, los costes y beneficios de la salida o la permanencia en el país, los factores que intervienen en la elección de pareja, el papel de las nuevas tecnologías en estos procesos y la consideración de la noción de mercantilización asociada a este nuevo mercado sentimental global, así como las nociones y expresiones de amor, intimidad y sexualidad que tales relaciones entrañan, su incidencia en los roles identitarios, especialmente de género, y su relación con procesos de divorcio e inestabilidad conyugal, además de la consideración de las parentalidades mixtas y los procesos, en fin, de comunicación y de negociación (inter)cultural. 
Las investigaciones recientes han hecho hincapié, asimismo, en los nuevos patrones de mercantilización y el crecimiento de los negocios vinculados a la búsqueda de pareja transnacional, en lo que bien podríamos denominar un "supermercado matrimonial global". Más específicamente, los denominados ciberromances y el desarrollo de las relaciones románticas en línea se han constituido en una importante área de estudio, con un cuerpo de literatura creciente. Dentro de esta perspectiva se ha documentado, por parte de diversos autores, que muchos aspectos de la intimidad y de las relaciones personales han ido comercializándose cada vez más explícitamente vinculados a los procesos globales de mercantilización. En términos marxistas, la mercantilización hace referencia a los procesos de asignación de valor a bienes o servicios que previamente se encontraban fuera del mercado.

En este sentido, la intimidad o las relaciones íntimas pueden ser tratadas, comprendidas o pensadas como si hubieran entrado a formar parte del mercado $y$, en consecuencia, hubieran pasado a ser susceptibles de ser compradas o vendidas; empaquetadas y publicitadas; objeto de fetichismo, comercializadas u objetivadas; consumidas o con un precio o valor asignados; $y$ vinculadas en muchos casos a la movilidad transnacional y los procesos migratorios, formando parte del flujo capitalista global de mercancías. La metáfora del mercado, en efecto, permite explorar algunas implicaciones del desarrollo de las relaciones románticas en la red como la objetivación de las potenciales parejas y la mercantilización de uno mismo y de los demás como productos para la venta, la valoración, la compra o el descarte, así como hablar de la mercantilización de la intimidad o del afecto.

Nuestro trabajo, por lo tanto, constituye una aportación a esta emergente literatura que permite conocer las características que adoptan en España y en las parejas mixtas de españoles y extranjeros buena parte de las cuestiones que se han presentado hasta aquí en relación con otros países. 


\section{Movilidad y vida cotidiana en Cataluña: etno-geografía de los espacios y tiempos metropolitanos (CSO2012-35425)}

Joan Josep Pujadas

Viajar diariamente, desplazarse entre el trabajo y la residencia, no es una opción de vida, sino un imperativo basado en la deslocalización creciente entre vivienda y lugar de trabajo, dos variables que la mayoría de la población no puede controlar. Como rasgo definidor de la vida cotidiana, queremos profundizar en los significados y en el simbolismo que se asocian a esta práctica. Nuestra hipótesis de partida es que para la mayoría de los ciudadanos (commuters, comarcantes) el hecho de viajar no es (necesariamente) un castigo. Partimos también del supuesto de que viajar en el menor tiempo posible tampoco es, en la mayoría de las ocasiones, el requisito principal. Y ello porque el tiempo del viaje no es percibido en la mayoría de los casos como un tiempo vacío o perdido, sino que constituye más bien una plataforma espacio-temporal personal donde se puede conseguir sosiego, privacidad, descanso, tiempo adicional para seguir trabajando y, en muchos casos, relaciones personales, con valor estratégico desde el punto de vista de adquisición de capital social.

Nuestros objetivos de investigación son los siguientes:

1. Establecer jerárquicamente los criterios que llevan a los ciudadanos a elegir uno $u$ otro tipo de transporte en sus desplazamientos cotidianos y no cotidianos: duración del viaje, coste, confortabilidad, sociabilidad, privacidad.

2. Establecer si el commuting de media distancia (como el que separa Barcelona de Girona, Tarragona y las poblaciones de la RMB) se vive como una situación anómala y pasajera o, por el contrario, si constituye una plataforma de privacidad o de sociabilidad buscada y fuente de compensaciones.

3. Establecer un perfil sociodemográfico de los protagonistas de la movilidad a partir de sus características sociológicas, bien de tipo individual, bien en el contexto de las distintas estrategias personales en un sistema de movilidad familiar o del hogar. Para ello, los demógrafos del equipo están trabajando con 
los resultados de la Enquesta de Condicions de Vida i Hàbits de la Població (IERMB, 2011).

4. Establecer si existen conexiones entre el radio espacial en que se desenvuelve la movilidad cotidiana (trabajo o estudio) y los horizontes territoriales en que se desarrolla la movilidad no cotidiana (aprovisionamiento, ocio, cultura, servicios) para caracterizar el espacio de vida de la población metropolitana de Cataluña.

5. Establecer, a partir de las conexiones analizadas en el punto anterior y en su marco territorial, cuál es el espacio de vida de la población metropolitana según su ámbito de residencia.

6. Caracterizar el espacio de vida de la población residente en la región metropolitana de Barcelona y comprobar si su comportamiento territorial es similar o extrapolable al de los residentes de otras dos regiones funcionales en proceso de metropolización: por una parte, el Camp de Tarragona y, por otra, las comarcas gerundenses.

7. Establecer en qué medida la urbanización difusa de la población metropolitana es generadora de carencias de sociabilidad y en qué medida el transporte cotidiano suple de alguna manera esas carencias.

8. Establecer en qué medida las prácticas metropolitanas van redefiniendo con su dinámica constante las fronteras entre centros, subcentros y periferias de la RMB y qué nuevas áreas de centralidad se van configurando.

9. Establecer los parámetros a considerar en los valores de utilidades de la variable tiempo. Se trata de analizar para qué espacios metropolitanos y para qué umbrales de tiempo puede tener un valor positivo el uso del transporte (relaciones sociales, lectura, espacio de introspección o de descanso, etc.).

10. Establecer, a propósito del transporte y los territorios sostenibles, cuáles son los parámetros valorados en prácticas de transporte más sostenible frente al uso individual del vehículo privado: compartir coche, cadena bicicleta-ferrocarril, a pie-ferrocarril y otras.

La investigación se encuentra prácticamente en su ecuador temporal, estando prevista su conclusión para inicios de 2016, de acuerdo con el cronograma acordado con el Ministerio (MINECO). Al no existir todavía unas conclusiones plausibles y fundamentadas, relacionaré los avances logrados en estos dieciséis meses de trabajo. 
Se han realizado 25 entrevistas en profundidad (de una duración promedio de 40 minutos) a commuters de media distancia; esto es, a personas que se desplazan desde Barcelona o alguna otra localidad de la primera o segunda corona metropolitana de Barcelona hacia Tarragona, Reus o Girona. Por ahora, nuestra muestra tiene una sobrerrepresentación de personal vinculado a la URV cuyo domicilio se ubica en la RMB. Esperamos poder completar una muestra de 75 entrevistas de estas características, tal como consta en la memoria del Proyecto.

Paralelamente a la realización de entrevistas, se están llevando a cabo trayectos en transporte público acompañando a personas cuya movilidad cotidiana se realiza dentro de los ejes territoriales antes señalados. Se trata de tener la oportunidad de observar la amplia gama de actividades desarrolladas en los trayectos de sus viajes, identificando aquellas actividades prevalentes $y$, sobre todo, recogiendo contactos con los conocidos y compañeros de viaje para captar hasta qué punto podemos hablar de grupos de sociabilidad ferroviaria o de autobús. Nos interesa detectar las estrategias utilizadas por estos viajeros cotidianos en el transporte intermodal, ya que muchos de ellos deben utilizar otro tipo de transporte antes y/o después del uso del medio de transporte público que cubre la distancia principal del trayecto. Observamos como el uso de la bicicleta es creciente, aunque todavía prevalece el uso del vehículo motorizado para llegar hasta la estación de origen, especialmente en el caso de las personas que habitan en núcleos suburbanos o en poblaciones sin transporte público.

Los antropólogos y los demógrafos del grupo de investigación hemos diseñado y realizado, mediante el apoyo de los vicerrectorados de Investigación, sendas encuestas al personal de las universidades de Lleida y Rovira i Virgili. Estamos pendientes de culminar este mismo proceso con la Universitat de Girona. Las dos encuestas acabadas y analizadas nos aportan perfiles muy interesantes de los usos y hábitos de movilidad del PDI y PAS de las respectivas universidades, así como sus opciones, voluntarias u obligadas, en relación con el uso de un tipo de transporte u otro. De manera general, el PAS de las dos universidades vive en zonas mucho más próximas a su lugar de trabajo que los miembros del PDI.

A pesar del uso prevalente del vehículo privado, existe una marcada tendencia al uso del transporte público cuando las distancias a cubrir diariamente superan los 35 o 40 kilómetros. El uso de la bicicleta se está extendiendo, es- 
pecialmente cuando la movilidad no supera los $10 \mathrm{~km}$. Hay un pequeño, pero significativo, grupo que utiliza la bicicleta antes y después del uso del tren o del autobús en viajes con un radio superior a los $80 \mathrm{~km}$. El uso del coche compartido, a pesar de las campañas institucionales que lo fomentan, es casi inexistente entre el PDI y el PAS de ambas universidades, a diferencia del caso de los estudiantes, que parecen usarlo de manera mucho más sistemática.

En cuanto a la encuesta al personal de la URV, la prevalencia del uso del vehículo privado (junto a las rutas a pie o en bicicleta) es muy elevada en el caso de lo que denominamos commuting de corta distancia; esto es, en los desplazamientos dentro del área metropolitana de Tarragona, que, a efectos prácticos y funcionales del proyecto, hemos definido como el territorio comprendido por las comarcas del Tarragonès y del Baix Camp, en cuyas capitales se ubican el 90\% de los centros de la URV. Por el contrario, en el caso de los desplazamientos de media distancia cuyo origen es la misma ciudad de Barcelona o los municipios de la primera corona metropolitana el uso del transporte público (sobre todo ferroviario) predomina de manera clara. Los desplazamientos desde municipios de la segunda y tercera corona de la RMB hacia el AMT se realizan, indistintamente, en vehículos privados y públicos.

Más allá del análisis de los medios de transporte, nos interesan las lógicas y estrategias, a nivel personal y familiar, que están implicadas en las formas de movilidad adoptadas. Estas lógicas y estrategias están relacionadas con los roles domésticos asumidos por cada persona en el seno de la familia, con los horarios laborales y con la accesibilidad de un tipo u otro de transporte y su precio. Por otro lado, estamos interesados en la narración de las actividades que se realizan durante los trayectos en transporte público y que marcan tanto las disponibilidades de tiempo libre de cada persona como las afinidades eventuales que se manifiestan entre compañeros de viaje, muchos de ellos vinculados a la empresa en que se trabaja.

Un interés especial en nuestra investigación viene marcado por el análisis de nuevas formas de movilidad intermunicipal como son el uso de la bicicleta (tanto como vehículo exclusivo como en el caso del transporte intermodal) y el del coche compartido (carpooling), que está adquiriendo creciente importancia entre la población más joven y entre aquellas personas que realizan viajes frecuentes de media o larga distancia y que buscan economizar gastos. El estudio 
de este último aspecto viene favorecido por la existencia de numerosas redes con presencia en internet.

Los documentos elaborados hasta ahora se limitan a un artículo y a tres comunicaciones en congresos o reuniones científicas, más un documento aparecido en una red de internet:

Pujadas, J.J. (2012), "Itinerarios metropolitanos: policentrismo, movilidad y trayectorias personales en la ciudad porosa", Biblio3W, vol. XVII, núm. 968 [en línea: <http://www.ub.edu/geocrit/b3w-968.htm>] (ISSN: 1138-9796).

Pujadas, J.J. y Tapada, T. (2013), "Ethno-geography of commuting in Catalonia: the role of neighbourhood choice in urban mobility", European Network for Housing Research Conference, Tarragona, junio de 2013.

Alberich, J. y Roquer, S. (2014), "El espacio de vida de la población catalana metropolitana. Un análisis a partir de la 'Enquesta de condicions de vida i hàbits de la población', 2011”, en XIV Congreso Nacional de la Población. Cambio demográfico y socioterritorial en un contexto de crisis, p. 486-497, Madrid, Grupo de Población de la Asociación de Geógrafos Españoles (ISBN: 97884-697-0997-9).

Pujadas, J.J. (2014), “Territoris nòmades. Mobilitat quotidiana de les persones a l'RMB", Translocacions: Jornades Internacionals, Barcelona, Arts Santa Mònica - Idensitat (30-31 de octubre de 2014). Pendiente de publicación.

El proyecto cuenta con una página web (<http://e-nomada.net/ $>$ ) y con una página de Facebook (<https://www.facebook.com/profile. php?id=100007047552660>), que son nuestra ventana abierta a la comunicación con aquellas personas interesadas en el campo de la movilidad. 


\section{Pràctiques locals i discursos globals en la reproducció de les comunitats rurals. Desenvolupament rural, agroecologia i sobirania alimentària $^{1}$}

\section{Montserrat Soronellas Masdeu}

Lobjecte d'estudi d'aquesta recerca és analitzar les condicions actuals de reproducció de les comunitats rurals, i també els discursos i les pràctiques que han sustentat el desenvolupament rural i l'apropiació de les bases ideològiques d'aquest discurs per part de les poblacions locals. Ens ha interessat conèixer les respostes locals a les condicions imposades per la globalització econòmica. La insostenibilitat del model clàssic de desenvolupament agrari i rural basat en l'expansió de l'agricultura productivista i industrialitzada (l'anomenada Revolució Verda) i la constatació que no ha contribuit a resoldre els problemes de reproducció que afecten les zones rurals, ha portat l'Administració (als països europeus, fonamentalment, per mitjà de les polítiques agràries comunitàriesPAC) a plantejar polítiques alternatives al productivisme industrial, que expressin la necessitat de combinar les innovacions tecnològiques amb la recuperació de les cultures agràries locals i les habilitats i els sabers de les formes de gestió tradicionals de la producció, la transformació i la comercialització de les produccions agràries.

D'una banda, cal tenir en compte el discurs de la sostenibilitat difós per la PAC mitjançant les polítiques de desenvolupament rural i els estímuls econòmics atorgats per prendre mesures agroambientals en els processos de producció agrària. D'altra banda, i un pas més enllà en la consciència ecològica $i$ ecologista, tenim el discurs de l'agroecologia que planteja la recuperació de les cultures agràries locals i sostenibles; i el de la sobirania alimentària, que treballa perquè els pobles tornin a ser com més sobirans millor en termes de producció

\footnotetext{
1 Aquesta recerca ha comptat amb el suport econòmic de la convocatòria 2012 dels ajuts per fomentar la incorporació i visualització d'investigadors emergents 2012. LINE-2012 (Banco de Santander-URV). Han format part del grup de l'equip de recerca: Agustí Andreu, Verónica Anzil, Yolanda Bodoque, Gemma Casal, Dolors Comas d'Argemir, Mariantònia Monserrat, Maria Offenhenden, Montserrat Soronellas (IP) i Ramona Torrens, investigadors i investigadores vinculats al DAFITS en aquest període.
} 
alimentària. Aquests plantejaments han anat construint sensibilitats entre la població. Les conseqüències són diverses: ha crescut el nombre de consumidors de productes ecològics; també el nombre de productors ecològics en tots els sectors productius; s'ha consolidat una xarxa d'agroturisme que contribueix a la sostenibilitat de les explotacions i a la fixació de població rural; s'han recuperat les produccions artesanes tradicionals; s'ha revaloritzat el comerç de proximitat (l'ecogastronomia, els aliments de quilòmetre zero...); es recuperen varietats locals que havien estat substituïdes per d'altres de més productives; proliferen fires, mercats i jornades que difonen i comercialitzen les produccions locals. En definitiva, parlem de la presa en consideració de les produccions agràries i de les elaboracions agroartesanes alimentàries com una peça clau del model de desenvolupament de les zones rurals i, com un recurs essencial per a la reproducció social de les comunitats rurals.

Cada membre de l'equip ha participat en la recerca amb aportacions centrades en algun dels àmbits que hem esmentat que, en grans unitats analítiques teòriques, podríem delimitar així: (a) la producció de localitat en el context de la globalització; (b) l'agroecologia; (c) el desenvolupament rural i les noves ruralitats; (d) el patrimoni i els processos de patrimonialització. Cadascun d'aquests àmbits teòrics va aportar elements explicatius a les etnografies que van recollir pels investigadors i va fer evident que tots s'han de tenir en compte per explicar les condicions actuals de reproducció de les zones rurals i de les economies agràries.

Al llarg del temps de vigència del projecte (de juny de 2012 a juny de 2014) s'han dut a terme trobades mensuals de discussió teòrica, metodològica i de debat sobre les resultats de les recerques respectives. Cadascuna d'aquestes sessions s'ha ubicat en algun dels àmbits teòrics descrits, $i$ ha aportat elements de reflexió a partir de les etnografies recollides i treballades pels investigadors. En els dos anys que ha durat el finançament del projecte s'han realitzat tasques de treball de camp, però sobretot treball bibliogràfic i documental que, tal com demanava la convocatòria de l'ajut rebut, permetés construir les bases d'un estratègia metodològica comuna amb les quals s'ha de recollir de manera coordinada la informació etnogràfica que ha de permetre donar resposta a les preguntes de la recerca.

Amb aquest objectiu al capdavant, es va organitzar una jornada de recerca al mes de novembre de 2013: "Ruralitats emergents i (agri)cultures urbanes", en la 
qual vam poder debatre certs aspectes directament amb investigadores i investigadors de l'àmbit de l'Estat espanyol (Universitat de València, UAB, UNED i Universitat de Valladolid) que actualment estan treballant en el mateix objecte de recerca. En aquesta jornada ens plantejàvem una qüestió essencial per al projecte futur que és la consideració que la societat rural està continguda dins de la urbana i que hem de reflexionar sobre la ruralitat des dels processos d'urbanització dels espais, dels estils de vida i de les consciències. La jornada proposava una reflexió sobre la diversitat de la ruralitat contemporània, en el context de la globalització, i sobre el plantejament de situacions noves, conceptes i consciències que emergeixen de les formes de vida urbanes i que incideixen sobre la reproducció dels pobles i de les zones rurals.

En les ponències i en el debat de la jornada, es va posar en evidència que les ruralitats actuals emergeixen de la globalització; que la ciutat i els processos urbanitzadors marquen el ritme de la societat actual, també el del camp. Tant és així que les ruralitats d'avui estan configurades en bona mesura a partir dels processos urbanitzadors i dels models de vida urbana. Els canvis estructurals que han sofert els pobles en el decurs del segle xx: la despoblació, l'envelliment i la desagrarització estan directament relacionats amb la urbanització. Però també ho estan fenòmens nous i més recents, i contraposats, com la repoblació rural, la terciarització econòmica, o l'agrarització, que hem de relacionar amb la ciutat i amb les cultures que neixen dels entorns urbans des d'on es desplacen al camp o hi arrelen.

Aquest debat ens ha portat a la preparació d'un nou projecte de recerca"Iniciatives emergents en les noves ruralitats. Projectes locals i discursos globals" que té com a objecte d'estudi les iniciatives emergents (econòmiques, socials i culturals) que han sorgit, especialment en l'última dècada, en les àrees rurals i que es plantegen com a maneres d'afrontar la crisi estructural (i conjuntural) que experimenten els pobles i els recursos de reproducció tradicionals. L'estudi de com sarticulen aquestes iniciatives emergents i de les formes concretes que adopten, posa de manifest el paper de l'Estat i del mercat, però també l'acció de les poblacions locals en termes d'adaptació o resistència i el procés de generació de noves imatges i valors, i també la demanda de nous serveis i productes. El projecte pren com a hipòtesi de partida que aquestes iniciatives sorgeixen de la combinació entre els elements culturals (en sentit ampli) que tradicionalment havien proporcionat les garanties de reproducció social que havien significat $\mathrm{i}$ 
cohesionat les comunitats rurals; i, en segon lloc, factors perfectament inscrits en les condicions de vida contemporànies i de la societat globalitzada: el turisme, les migracions internacionals o la sensibilitat ecològica. La combinació d'aquests dos grups de factors, la cultura agrària i rural tradicional, d'una banda, i les formes de vida, les sensibilitats contemporànies i la cultura científica, de l'altra, han estat utilitzades per les poblacions rurals per tirar endavant projectes, alguns ja de consolidats i molt coneguts (turisme rural, agrotransformació o agricultura ecològica) i, d'altres, de pioners, emergents, menys coneguts, fins i tot, més domèstics (experiències agroecològiques de petit format, experiències de recuperació de biodiversitat, educació agrària, etc) que han contribuït a palliar les dificultats de reproducció d'una ruralitat que avui és molt diversa. Tot plegat revela noves formes de governança i territorialització aplicades a les àrees rurals que han de ser investigades.

Lexploració de les iniciatives, especialment les que s'han dut a terme en els darrers quatre anys i les que s'han inscrit en el context de la crisi econòmica que afecta Europa, ens ha d'aportar una visió molt interessant de la capacitat de resiliència de les zones rurals. L'experiència de crisi estructural i secular de les àrees rurals i les alternatives dutes a terme a partir de la combinació d'elements tant de les cultures locals, com de les condicions globals, ens resulten útils per explorar mesures que ajudin al moment actual a aprendre i comprendre fins a quin punt la cultura pot actuar com un factor de cohesió social.

Actualment, alguns membres del grup de recerca estan treballant en el procés de selecció de les unitats d'observació de la recerca (iniciatives locals significatives en relació a l'objecte d'estudi) i en fase de treball de camp, elaborant les etnografies dels casos seleccionats, els quals s'investiguen des d'una perspectiva situacional però també processual per obtenir una bona descripció etnogràfica de les iniciatives que s'han estudiat i comprendre com es creen i recreen les estratègies relacionades amb la redefinició de la ruralitat tot considerant les transformacions socioculturals, econòmiques, polítiques i demogràfiques que han afectat les àrees s'han estudiat en el transcurs del segle xx i fins avui. 


\title{
"Encounters and Engagements": el primer congrés mundial d'antropologia mèdica, organitzat a la URV al juny del 2013
}

\author{
Oriol Romaní i Josep M. Comelles
}

Els dies 12, 13 i 14 de juny de 2013 al Campus Catalunya de la URV es va organitzar el que ha estat el primer congrés mundial d'antropologia mèdica, sota el títol "Encounters and Engagements: creating new agendas for Medical Anthropolog". Es va precedir d'una trobada específica de la Medical Anthropology Young Scholars Network, de l'EASA, que tenir lloc el dia abans. Aquest congrés, organitzat per l'EASA Medical Anthropology Network, la Society for Medical Anthroppology de l'American Anbropological Association i la Universitat Rovira i Virgili, va acollir 640 acadèmics i professionals de 51 països diferents.

El fet que sorganitzés a Tarragona no fou casual. Lantropologia mèdica — juntament amb l'antropologia urbana - ha estat una de les "marques de la casa" de l'antropologia tarragonina des de bon començament. Podem dir que la data fundacional se situa al desembre de 1982, quan prop d'uns 150 antropòlegs - i uns quants sociòlegs i metges - de tota la Península ibèrica i algun de fora, vam assistir a les I Jornades d'Antropologia de la Medicina, organitzades per l'Institut Català d’Antropologia. Ja aleshores, en Lluís Mallart va exercir de "pare fundador", acompanyat d'en Josep M. Comelles i d'altres membres (ara "històrics") de l'actual Departament d’Antropologia, Filosofia i Treball Social de la URV. La presència de l'antropologia mèdica es va anar consolidant en la docència i en la recerca, fins a arribar a la creació del Màster en Antropologia de la Medicina, títol propi que es va iniciar el 1994 sota la orientació dels nostres mestres Lluís Mallart, Eduardo Menéndez i Tullio Seppilli. Creiem que aquest va ser un moment significatiu, ja que Tarragona es converteix en la capital d'una antropologia mèdica realitzada des dels àmbits llatins, que finalment serà reconeguda per la més hegemònica, l'anglosaxona. A partir del 2006, la creació del Màster Oficial en Antropologia Mèdica assenyala la consolidació d'aquest camp a la URV, però és evident que la posició estratègica de la URV li ha permès, d'una banda, fer de lligam entre el Sud d'Europa i Llatinoamèrica, i de l'altra, amb les antropologies mèdiques del Nord d'Europa (EASA) i dels Estats Units (AAA), com s'ha fet palès en la organització d'aquest congrés. 
Per què "Trobades i Compromisos"? Pel que fa al primer aspecte, més enllà de les trobades inherents a reunions com aquesta, suggereix també convergències que es poden generar tant entre les diferents persones involucrades en els processos de salut, malaltia i atenció, entre els professionals de diferents disciplines i els de tradició popular, o "cruilles" entre estructures i dinàmiques socials amb sentits, sentiments i emocions, en què s'involucren desitjos, plaers i sofriments. Com es deia en la presentació de la conferència, aquestes cruilles "també poden comprometre agents gairebé humans o no humans — microbis, líquids destilllats, productes farmacèutics, tecnologies mèdiques, experiments, institucions governamentals, organitzacions no governamentals, armes i paraules (entre molts altres). Poden ser reals, virtuals o imaginaris, actius o passius. I poden generar canvis de tota mena i donar lloc a noves identitats, formes i trajectòries."

I continuava dient pel que fa als compromisos que "evoquem l'ampli historial de compromís amb els processos de canvi dels antropòlegs mèdics, en diferents rols; en alguns casos, colllaboren amb institucions biomèdiques per adaptar els seus programes a les realitats socials, en altres casos, s'acoblen amb els receptors per donar veu a les seves preocupacions. Per mitjà d'aquests compromisos amb els diversos actors, els antropòlegs mèdics han desplegat una sèrie de noves maneres d'investigar."

A partir d'aquestes orientacions genèriques es van plantejar deu grans línies temàtiques, en les quals cal situar les aportacions dels participants, que van ser: reconfiguració de les pràctiques mèdiques; itineraris terapèutics; noves collectivitats en salut; incertesa, intuïció i confiança; cicles de vida i salut; experimentacions en salut i noves configuracions del que és (in)humà; violència i agency; fluxos transnacionals/ transculturals; poder, gènere i raça; i els límits del cos, pràctiques i (nous) plantejaments fenomenològics. Això va contribuir que les discussions fossin més riques i va ajudar que transcendissin les temàtiques específiques, i malgrat que potser en algun moment precisament per això hi van haver, en un extrem, redundàncies temàtiques, i en l'altre, algunes dificultats de comunicació entre temes molt diferents, creiem que els avantatges van superar els inconvenients. En total es van presentar 506 comunicacions, que es van distribuir entre 53 panels.

$\mathrm{Hi}$ va haver només tres conferències plenàries: la primera, a càrrec de $\mathrm{Su}$ san Reynolds Whyte, com a representant de la generació fundacional, a la qual pertany Lluís Mallart, a qui es va fer un homenatge aquell mateix dia; la intermèdia, d'Esther J. Langdon, que malgrat que és nord-americana, fa 35 anys que 
treballa al Brasil i per les seves temàtiques representava d'alguna manera els sectors menys hegemònics; i l'última, de Rose M. Moro, que va posar de relleu les aplicacions professionals, ja que és una psicoterapeuta d'origen espanyol especialitzada en diversitat cultural que viu i treballa a París.

A més, es van presentar 25 pòsters, 9 tallers tecnicometodològics - sobre metodologies mixtes, un vídeo participatiu, anàlisi de xarxes, etc.-, un programa de cine amb 18 pellícules -entre les quals La dansa als esperits, d'en Ricardo Íscar a partir del llibre d'en Mallart o Lejos de los árboles, de Jacinto Esteva-, dues taules rodones, una sobre l'ensenyament de l'antropologia mèdica i l'altra sobre les publicacions en aquest camp, i una exposició al CRAI del Campus Catalunya sobre el desenvolupament de l'antropologia mèdica a partir de les seves publicacions, amb una mostra de revistes i llibres.

Malgrat que tot plegat va ser molt interessant, és evident que si no hi hagués hagut el "bon rotllet" informal que sempre hi sol haver quan aquestes reunions estan ben organitzades, i que va ser afavorit pels actes socials que van acompanyar el congrés, aquest no hauria pogut assolir cap dels objectius principals, el de les trobades, que, quan són psicològicament significatives, amb els seus afectes i emocions fan com de "gasolina" que contribueix a poder dur a terme projectes comuns.

En definitiva, es van poder compartir molts projectes i idees, malgrat les dificultats de comunicació en alguns moments, pròpies d'una reunió com aquesta. Alguns vam pensar que entre antropòlegs, especialistes de la diversitat cultural, no es podia donar per obvi que només s'havia de parlar anglès, malgrat que aquesta era la nostra actual lingua franca en el terreny científic, i ens vam esforçar perquè als panels on es posés la qüestió es pogués discutir també en les dues altres grans llengües en què es du a terme la disciplina, és a dir, l'espanyol i el portuguès. Potser aquest petit detall va contribuir a fer més presents, des d'un punt de vista sensible i no només intel.lectual, alguns dels grans temes objecte de la conferència, com la diversitat cultural, les relacions de poder, les transformacions dels límits entre realitats molt ben establertes en la modernitat (com naturalesa/ cultura, cos/ context...), i també entre maneres d'analitzar tots aquests processos; en fi, perspectives que malgrat que qüestionen les nostres especialitzacions disciplinars, ens poden ser molt útils per ajudar a transformar la realitat que ens envolta. Creiem que, en aquest sentit, "Encounters and Engagements" ha estat una fita molt significativa. 


\title{
De gladiadores y antropólog@s. Breve reseña sobre el XIII Congreso de Antropología "Periferias, fronteras y diálogos"
}

\author{
Natalia Alonso Rey
}

El XIII Congreso de Antropología de la FAAEE se celebró por primera vez en la ciudad de Tarragona del 2 al 5 de setiembre de 2014, organizado por L'ITA, Associació d’Antropologia, con el apoyo del Departament d'Antropologia, Filosofia i Treball Social (DAFITS) de la Universitat Rovira i Virgili. En esta edición cerca de 500 antropólogos y antropólogas de todo el Estado español, así como de algunos países de Latinoamérica y Europa, se encontraron convocados bajo el lema "Periferias, fronteras y diálogos". Además de la elevada participación y de la riqueza y diversidad de las reflexiones antropológicas que allí se presentaron, el éxito del Congreso fue notorio también por el espíritu de camaradería reinante en varias de las actividades, así como por la dedicación con la que desde Tarragona se asumió la organización de este evento.

\section{Cuatro días de diálogos y encuentros}

El lema del Congreso "Periferias, fronteras y diálogos" convocó a la discusión en torno a ejes temáticos que surgieron de la reflexión sobre la posición del centro que nos acogía. Siendo Tarragona en sus inicios un lugar de producción de conocimiento antropológico "periférico" ante otros "centros" del Estado español (que a su vez resultaban periféricos para los centros europeos y estadounidenses), se llamaba a reflexionar sobre periferias y fronteras metodológicas, teóricas, geográficas y temáticas, y a contribuir al diálogo en un mundo que aparentemente diluye centros y periferias pero que mantiene formas hegemónicas que aún es necesario contestar (también a nivel disciplinar y académico), remarcando la pertinencia y la necesidad de realizar aportes desde la mirada antropológica.

La conferencia inaugural del congreso, pronunciada por el Dr. Joan F. Mira, nos situaba de lleno en estos ejes temáticos tanto por la elección del conferenciante (cuya trayectoria académica desnuda la rigidez de las fronteras discipli- 
nares) como por el tema de su exposición. Sus reflexiones en torno a la palabra, el concepto y el dominio de aquello que cae bajo el rótulo cultura interpela el núcleo de nuestra disciplina. El Dr. Mira realiza en su exposición ${ }^{1}$ un ejercicio de observación de lo que es considerado socialmente como cultura, y se detiene a reflexionar sobre la relación entre "cultura" y poder, aquella que permite nombrar y definir las fronteras entre lo que entra en dicho dominio y lo que queda en sus periferias. Esto obliga a considerar la importancia de las decisiones sobre el valor y de quienes las toman, sin dejar de lado la observación de aquello que funciona como cultura en nuestras sociedades. La constatación de la omnipresencia en la vida cotidiana de elementos considerados como "cultura" lleva al Dr. Mira a afirmar que esta podría ser considerada como la religión del tiempo presente.

Justamente en el terreno de lo religioso, o mejor dicho en las periferias religiosas, nos situaron los ponentes en el segundo día del Congreso, el Dr. Joan Prat y el Dr. Ramón Sarró, mientras que en el tercer día la Dra. Josepa Cucó y el Dr. Gary McDonogh ubicaron sus ponencias en las periferias (y centros) urbanas. Las cuatro ponencias evidencian que fijar la mirada en lo que ocurre en la periferia no solamente nos permite dar cuenta de aquello que ocurre en el centro, sino también estar atentos/as a potenciales oportunidades de cambio que surgen de espacios fronterizos y/o liminares y que nos obligan a estar alerta sobre el juego entre aquello visible y lo invisible o invisibilizado.

La conferencia de clausura, a cargo de la Dra. Victoria Goddard, nos presentó dos ejemplos desde los que analizan los efectos del capitalismo contemporáneo en relación con la globalización, el trabajo y el empleo en materia de identidades de género y diferencias generacionales. Estos ejemplos explicitan también las dificultades a la vez que los beneficios del trabajo etnográfico al abordar temas complejos como los que propone. La autora recuerda que para comprender las vidas cotidianas es necesario no perder de vista relaciones $y$ conexiones globales que producen continuidades y rupturas que deben ser introducidas en el análisis de procesos contemporáneos.

La presente edición del Congreso de la FAAEE optó por organizarse en torno a la modalidad de simposios. Se organizaron un total de 21 simposios

1 Las ponencias y los resúmenes introductorios a los simposios se encuentran disponibles en el libro Periferias, fronteras y diálogos. Una mirada antropológica a los retos de la sociedad actual; los textos de las comunicaciones presentadas, en el Libro de Actas del XIII Congreso de Antropología. Ambos están accesibles de manera electrónica en www.publicacionsurv.cat. 
en los que se presentaron más de 300 comunicaciones. Un repaso a estos nos permite observar la emergencia y consolidación de ciertos temas, la reactualización de temas clásicos a la luz de procesos y debates contemporáneos (aquí cabe señalar también la importante cantidad de comunicaciones centradas en procesos y efectos relacionados con la actual crisis económica) y la preocupación por la revisión y el seguimiento de la práctica profesional y académica en materia de formación y de ética en la disciplina.

Sin duda, un elemento que sirve para tomarle el pulso a nuestra disciplina es el elevadísimo número de propuestas de comunicación recibidas (abstracts), que en algunos simposios duplicaba o triplicaba el número posible de comunicaciones a aceptar. Como consecuencia del elevado interés se ofreció a los/las coordinadores/as doblar las sesiones para dar cabida a un número mayor de comunicaciones, propuesta que fue aceptada por la mayoría de ellos, pero que igualmente no pudo evitar que varias comunicaciones se quedaran fuera.

Asimismo, es interesante notar que algunos simposios han señalado explícitamente la ausencia de comunicaciones sobre algunos de los ejes temáticos previstos o la readecuación de los temas inicialmente propuestos a la luz de las comunicaciones recibidas, lo cual aporta datos interesantes para analizar posibles temas infraabordados o emergentes, así como la necesidad de revisar continuamente nuestros conceptos y categorías analíticos.

La programación académica se completó con cuatro actos académicos paralelos a los simposios: el acto de homenaje a Julio Caro Baroja, la presentación de la Cátedra Ángel Palerm, la constitución de la Red de Antropología Ambiental y un acto en torno al reconocimiento y los criterios de calidad de los documentos no textuales en antropología. Se exhibieron documentales etnográficos — "La ventana de los Andes" y "Legna: habla el verso saharaui"-; se realizaron presentaciones de novedades editoriales durante las tres primeras tardes del Congreso; y dos muestras fotográficas permanecieron en exhibición durante todo el Congreso - "Vientos del Este", de Eva Parey, y "Más frágiles que una burbuja”, de Andrea Lolicato, ambos ex alumnos del DAFITS-.

Durante la inauguración del Congreso el profesor Joan Prat señaló en su intervención la importante misión de los congresos de antropología como espacios de sociabilidad. Sin lugar a dudas, la organización se tomó en serio esta característica nada menor y planificó diversas actividades recreativas que favorecieron el encuentro entre colegas. 
Tarragona ofreció un escenario inmejorable al respecto y puso al servicio del Congreso sus sitios más impresionantes y algunos de sus mejores recursos: cóctel en Casa Canals, actuación castellera de Xiquets de Tarragona en la Plaça Reial, actuación de "Quico, el Cèlio i el Mut de Ferreries" en el barrio marítimo del Serrallo, visitas guiadas por el Casco Antiguo (que debieron duplicar sesiones ante la enorme demanda), así como la inolvidable tarde en el anfiteatro, donde presenciamos un simpático - y no poco excéntrico- espectáculo de recreación de luchas de gladiadores. Debo confesar a título personal que pedir la salvación o muerte de gladiadores en la arena de un anfiteatro romano no era algo que imaginara hacer, y menos dentro de las actividades de un congreso de antropología (¿o sí?). Esta fue una de las tantas agradables sorpresas en el curso de este, junto con la constatación de la rapidez con la cual antropólogos y antropólogas agotamos las provisiones de bebidas espirituosas en los dos refrigerios ofrecidos, y la notable entrega en la pista de baile de varios de los y las congresistas en el encuentro en la discoteca.

\section{Entretelones}

He sido testigo de una parte de los entretelones de esta edición del Congreso de la FAAEE (que en mi caso ha sido la primera), dada mi condición de becaria durante seis meses para dar apoyo a tareas organizativas de este. Creo que es mi posición relativamente periférica la que me convertía en idónea para escribir una crónica sobre este, ofrecimiento que he aceptado encantada y para el cual me han dado libertad total. Dado que el Congreso nos ha convocado a reflexionar sobre estas cuestiones, creía necesario comenzar la segunda parte de esta breve reseña haciéndolas explícitas.

Sin duda, una de las caras menos visibles del Congreso reside en los entretelones de su organización, que se iniciaron justo al apagarse las luces del Congreso de León y que aún hoy — a poco más de un mes de haber finalizado el Congreso de Tarragona - no se han extinguido del todo. El volumen de trabajo de organización es considerable, y el éxito en la celebración del Congreso fue la mejor recompensa a dicho esfuerzo. Durante los cuatro días en que el trabajo de tres años se ponía a prueba, la colaboración grupal fue extraordinaria y contó con un aliado inesperado, que resultó imprescindible a la vez que extremadamente exigente: un grupo de whatsapp compartido por las personas 
implicadas más directamente en la organización donde se comentaban problemas, logros y casi el "minuto a minuto" del Congreso. Este aliado tecnológico no solamente ayudó en la organización, sino que también permitió crear un sentido de colaboración, participación y satisfacción colectiva (iy catarsis colectiva en ciertos momentos también!) que estoy convencida de que los y las asistentes al Congreso pudieron percibir y que también es parte de su éxito.

Un elemento que marcó el Congreso y es ineludible en una crónica sobre este fue la dificultad para hacer frente a los gastos económicos de la inscripción que manifestaron varias personas interesadas en él, lo cual refleja la grave situación económica que afecta a colegas e instituciones universitarias del Estado español. Sin duda, esta XIII edición del Congreso de la FAAEE, como más de una vez se comentó durante la organización, ha sufrido y evidencia el impacto de la precarización y los recortes que afectan a la educación. Lamentablemente, en este sentido el panorama futuro es poco alentador.

El último apunte que deseo realizar, con vistas a las futuras ediciones, es acerca de la necesidad de seguir reflexionando sobre la manera de combinar participación, tiempo y debate en los simposios o en las modalidades de participación que se seleccionen, así como también de hacer accesibles y perdurables las aportaciones de los congresos. Tanto la limitación de tiempo como el requisito de presentar el texto de la comunicación provocaron algunas reacciones encontradas antes y durante el Congreso. Cabe reflexionar entonces sobre los objetivos y las modalidades de participación, tarea a la cual creo que todos/as los/las asistentes en los diversos roles asumidos estamos convocados. Asimismo, considero que somos capaces de aportar ideas o acciones para combinar rigor, innovación y flexibilidad a la luz de una disciplina que crece y que merece espacios de discusión y de encuentro como el que tuvimos el gusto de compartir en Tarragona.

Tanto en la dimensión académica como en la de sociabilidad, esta edición del Congreso de Antropología ha cumplido con creces las metas que se había propuesto y seguramente ha servido para gestar futuras colaboraciones académicas, consolidar investigaciones y forjar nuevas (y reforzar viejas) amistades. Y, no menos importante, nos ha dado la oportunidad de pedir la salvación de una gladiadora en las arenas de Tárraco y poder ir a celebrarlo a ritmo de bachata y música pop hasta las tantas. 


\section{Los congresos de antropología de la FAAEE; una breve reflexión ${ }^{1}$}

Joan Prat i Carós

Para mí es un placer y una responsabilidad que mis amigos y colegas del DAFITS (Departamento de Antropología, Filosofía y Trabajo Social) y del ITA, Asociación de Antropología, me hayan nombrado presidente de honor de este XIII Congreso de Antropología de la FAAEE y les agradezco la gentileza de todo corazón; gentileza que, además, me ofrece la oportunidad de dirigir unas palabras iniciales de bienvenida a todas las/los congresistas presentes.

Junto con el encargo de preparar esa alocución inicial, recibí una advertencia severa: “iEscucha bien: tienes quince minutos para hablar, ni uno más, que te conocemos...!". Prometí obediencia y me pareció que una buena manera de aprovechar los minutos concedidos podía ser una breve reflexión sobre los catorce congresos estatales que han precedido al que hoy inauguramos en esta Facultad de Letras de Tarragona. Dividiré la exposición en dos apartados: los congresos desde la perspectiva profesional y los congresos como espacios de sociabilidad.

\section{Los congresos como marcos profesionales}

Como muchos ya sabéis, nuestra historia congresual comenzó con la Primera Reunión de Antropólogos Españoles, que se celebró en Sevilla a finales de enero y primeros de febrero del año 1973, es decir, hace un poco más de cuarenta años. Al encuentro de Sevilla siguió, en 1974, la II Reunión de Antropólogos Españoles, celebrada en Segovia pero organizada por departamentos de Madrid, y, tres años después, en 1977, Claudi Esteva convocaba el Primer Congreso Español de Antropología, en Barcelona.

El planteamiento de estos tres encuentros iniciales siguió el modelo clásico de la antropología norteamericana, que agrupaba (o agrupa) disciplinas diversas como la arqueología, la antropología biológica y la etnohistoria, además de la antropología cultural y social propiamente dichas.

1 Preparé estas páginas como discurso oral. Al reescribirlo no he modificado esta intención inicial. 
En Barcelona (1977), se produjo un giro importante: los jóvenes antropólogos del momento (los que ahora andamos por los sesenta y pico y los setenta años y que en la terminología acuñada por Josep $\mathrm{M}^{\mathrm{a}}$ Comelles constituimos la segunda generación) se agruparon, o nos agrupamos, en torno al simposio de Sociedades Campesinas y plantaron cara a la autoridad de los catedráticos de Sevilla, Madrid y Barcelona, que no solo habían tenido un papel protagonista en el arranque de la antropología en el Estado, sino que también habían promovido estos primeros eventos institucionales. Pienso que, metafóricamente, se podría considerar el Primer Congreso de Antropología de Barcelona como el del "otoño de los patriarcas" (parafraseando, claro está, un título de G. García Márquez), ya que los patriarcas aludidos dejaron de tener el papel relevante que habían tenido como organizadores hasta aquel momento. Ello no supuso una merma de su influencia, que se continuó ejerciendo en los tribunales de oposición y en la capacidad de adjudicar plazas en el mundo universitario.

La convocatoria siguiente, en Madrid, en el año 1981, corrió a cargo de la Asociación Madrileña de Antropología y allí se acabó de discutir y perfilar la creación de la Federación de Asociaciones de Antropología del Estado Español (FAAEE), que se convirtió en la responsable de las convocatorias futuras. ${ }^{2}$

Una mirada panorámica sobre los programas de mano y los volúmenes de $\operatorname{actas}^{3}$ de los catorce encuentros habidos hasta el momento pone de relieve algunos aspectos y temas que paso a comentar brevemente.

La primera constatación es que se han organizado congresos de antropología en toda la geografía del Estado y que prácticamente todos los grupos consolidados de profesionales se han responsabilizado de dichos encuentros: Sevilla (en dos ocasiones), Madrid (en Segovia y en Madrid mismo), Barcelona y Donosti, también por duplicado, y Alicante, Granada, La Laguna (Tenerife), Zaragoza, Santiago de Compostela y León (organizado este último por la Asociación de Antropología de Castilla y León "Michael Kenny”), y, ahora, Tarragona, una única vez.

Después de mencionar las ciudades, los tiempos. La periodicidad trianual se ha respetado escrupulosamente, aunque han cambiado las épocas y fechas de los encuentros: si los dos primeros fueron en invierno, después se pasó a la

2 De todas formas, hasta el Congreso de Alicante, en 1987, no aparecen las siglas de la FAAEE.

3 Agradezco a Celeste Jiménez de Madariaga y a Juan Agudo el envío de los trece libros de actas del Congreso de Sevilla de 2005 que no conocía. 
primavera (o justo antes de Semana Santa) para, a partir del Congreso de La Laguna (1993), quedar fijado definitivamente el mes de septiembre para efectuar los encuentros.

Un análisis en profundidad de los títulos y contenidos de los simposios de la totalidad de las actas permitiría detectar los cambios y evolución de los objetos y temas de estudio de la antropología española en sus poco más de cuarenta años de existencia. Obviamente, esa es una tarea compleja que no podré desarrollar aquí, por lo que me limitaré a reseñar algunos aspectos más ligeros o incluso anecdóticos.

Así pues, revisando programas y actas, destacan determinados profesionales que, ya sea como presidentes o secretarios de la FAAEE, o bien como organizadores o coordinadores de simposios, se repiten de forma sistemática. No he hecho un recuento exacto ni tampoco una estadística, pero sí puedo afirmar que nombres como el de Isidoro Moreno, Joan Josep (Juanjo) Pujadas, Teresa del Valle o Ubaldo Martínez Veiga son prácticamente fijos. Les siguen otras y otros como Jesús Contreras, Josep Ma Comelles, Josepa Cucó, Pablo Palenzuela, Alberto Galván, Verena Stolcke, Carmen Díez Mintegui, Txemi Apaolaza, Oriol Romaní, Dolors Comas d'Argemir, Anthony Arnhold o yo mismo, que también hemos sido de una notable asiduidad. Escorándonos un poco más hacia el cotilleo, se observa que determinados personajes que aparecen con mucha fuerza en momentos concretos después se eclipsan con la misma rapidez. Asimismo, es curioso constatar que en ciertos momentos y contextos se perfilan unas alianzas aparentemente sólidas a nivel de organización de simposios o mesas de trabajo que después se quiebran definitivamente; o también el fenómeno contrario, es decir, cuando profesionales que parecían enemistados, se reconcilian y se alían para organizar simposios $u$ otros eventos de forma conjunta.

Desde otra perspectiva, los congresos estatales han sido un marco adecuado para invitar a conferenciantes y ponentes extranjeros: Maurice Godelier se estrenó en el I Congreso de Barcelona (1977) y también en la ciudad condal tuvimos la oportunidad de conocer personalmente a Angel Palerm, Pedro Carrasco, Santiago Genovés y Lluís Mallart, figuras consagradas por aquel entonces. A estos les siguieron muchos otros, de los cuales selecciono una pequeña muestra: George Stocking, Adam Kuper, James (Jim) Fernández en diversas ocasiones, Rodolfo Stavenhagen, Stanley Brandes, Andrés Fábregas (también 
asiduo en las últimas citas), George y Jane Collier, William Douglas y Davydd Greenwood. También Josep Ramon Llobera y Joseba Zulaika, catalán y vasco respectivamente, que desarrollaron sus carreras profesionales en el Reino Unido y en Estados Unidos, han sido conferenciantes destacados. De todas formas, la lista de profesionales extranjeros que han acudido a nuestros congresos es mucho más larga y dejo constancia, sin pretensión de exhaustividad, en nota. ${ }^{4}$

Entre los presidentes de honor de algunos congresos figuran Julio Caro Baroja, José Miguel de Barandiaran o Claudi Esteva-Fabregat y quizás el caso más sorprendente fue el de Alicante (1987), ya que la presidenta de honor fue, ni más ni menos, que la reina. También se han dedicado sesiones de homenaje a José Alcina, Angel Palerm, Joaquín Costa, Julio Caro Baroja y a los grupos Etniker de Euskadi o la Xeneracion Nos de Galicia.

Desde otra perspectiva, revisando cronológicamente programas y libros de actas, se observan una serie de cambios a nivel de organización interna que en general ayudan a mejorar determinados aspectos. Por ejemplo, a lo largo de los años ochenta, en todos los congresos aparece el típico simposio de "temas libres" (el conocido cajón de sastre en el que situar todas aquellas comunicaciones difíciles de encajar en los simposios programados). Pues bien, a partir del Congreso de Granada (1990), los "temas libres" prácticamente desaparecen y son substituidos por los denominados "grupos de trabajo","grupos de discusión", "mesas de trabajo" o "mesas" a secas y así queda establecido para el futuro.

También con la idea de delimitar contenidos y perfilar temáticas, el Congreso de Barcelona (2002) se convocó con el lema "Cultura i política". La innovación tuvo éxito y continuidad y fue adoptada unánimemente. Así, las divisas de los cuatro últimos congresos han sido: "Culturas, poder y mercado" (Sevilla, 2005); "Retos teóricos y nuevas prácticas" (Donosti, 2008); "Lugares, tiempos, memorias (la antropología ibérica en el siglo xxi)" (León, 2011); y, ahora en Tarragona (2014), "Periferias, fronteras y diálogos".

Por lo que respecta a las publicaciones, hay también variedad considerable. En los cuatro primeros —Sevilla (1973), Segovia (1974), Barcelona (1977) y Madrid (1981) - se publicaron uno (o dos) volúmenes de actas; en los tres siguientes —Donosti (1984), Alicante (1987) y Granada (1990)—, no hubo

4 Pedro Armillas, Raúl Iturra, Tulio Tentori, Roger Bartra, Bruno Latour, Jeanette Edwards, Eduardo Archetti, Manuela Carneiro da Cunha, Lucy Cohen, Joao de Pina Cabral, Ruth Behar, Susan Tax, John Murra, Marie-Elisabeth Handman, Graça Cordeiro, Brian Juan O’Neill, Sidney Mintz, Jorge Freitas Branco, Christiane Stallaert, Britt-Marie Thuren y Antonio Medeiros. 
edición de actas, y será el colectivo de antropólogos canarios los que en el Congreso de La Laguna (1993) establecen por primera vez la modalidad de dedicar un volumen por simposio. Este ejemplo, costoso pero útil, será seguido en Zaragoza (1996), con otros ocho volúmenes, Santiago de Compostela (1999), con diez, y Sevilla (2005), con trece. En Barcelona (2002) se optó por actas electrónicas, modelo seguido también en León (2011) y Tarragona (2014). En estos dos últimos casos, junto con las actas electrónicas se han editado, en papel, sendos libros con las conferencias y ponencias encargadas. Periferias, fronteras y diálogos (2014) incluye, además, un amplio resumen de los 21 simposios, redactados por las coordinadoras y coordinadores de los mismos.

Con el tema de las publicaciones doy por finalizado este primer bosquejo que todo lector/a que lo desee puede completar con la información que figura en el anexo final.

\section{Los congresos como espacios de sociabilidad}

Además de los objetivos científicos que se suponen y presuponen en cada congreso, no es ninguna originalidad afirmar que dichos encuentros constituyen un marco privilegiado de sociabilidad. En otras palabras, los congresos brindan la oportunidad a todas las personas que compartimos profesión e intereses similares de vernos, estar juntos y conversar no solo de temas científicos, sino de otros múltiples aspectos, sin descartar los aspectos más personales, incluidas las penas y alegrías de cada quien. Recuérdese que no es nada infrecuente que en las conversaciones entre colegas aparezca aquel típico: "Tú y yo nos conocimos en tal congreso, ¿no te acuerdas?"

Evocar las historias de los congresos pasados y vividos acostumbra a generar lo que podríamos llamar "recuerdos flotantes", que pueden traducirse en flashes muy diversos. Echaré mano de algunos de los míos para ilustrarlo: me acuerdo, por ejemplo, de los desayunos opíparos que nos regalábamos en el Congreso de La Laguna (1993), en el Hotel Meliá Botánico de Puerto de la Cruz, en Tenerife, ágapes matinales dignos de un jeque árabe, de un magnate del petróleo ruso o de cualquier otro mafioso multimillonario.

He constatado, sin gran dificultad, que mis recuerdos flotantes se dirigen más a las noches que a las mañanas. En ningún momento me ha venido a la

5 Concepto inspirado en la "escucha flotante" de los psicoanalistas. 
mente algo así como: ‘Qué maravilla el simposio de 'temas libres’ del congreso tal o cual!, me cambió la vida e iluminó mi mirada antropológica para el resto de mis días.... En cambio, sí que recuerdo con fruición y cierta nostalgia haber cantado a cuatro voces madrigales del Renacimiento en una plaza solitaria de Segovia o de Santiago de Compostela en plena noche. También constituyen recuerdos inolvidables los callejeos nocturnos con un grupo de colegas, amigos y amigas por los barrios viejos de las hermosas ciudades visitadas: Sevilla, Granada, Donosti, Santiago, León...

En otras ocasiones, han sido los mismos organizadores de un congreso los que han programado visitas guiadas por una ciudad, cenas o cócteles colectivos en lugares emblemáticos, o también espectáculos programados, visitas a museos, conciertos, etc., en muchos casos favorecedores de momentos de sociabilidad y communitas intensos. En la misma dirección, tampoco han faltado las noches de "farra y alegría" bien regadas con gin-tonics, cubatas, vodka con naranja o whiskies que finalizaban con alguna que otra timba de póquer en la que algunos/as quedábamos desplumados sin misericordia pues también entre antropólogos y antropólogas hay tahúres ocultos...

En fin, noches agradables de discoteca y bailongo que podían favorecer el noble arte del ligue. Aquí, nuevos recuerdos flotantes:"en tal congreso ligué," en tal otro me ligaron" y, en un tercero, cuando ya tenía los anzuelos y las redes preparados para la pesca, apareció un pescador más hábil que yo que me dejó tirado, triste y sin recompensa final.

Los recuerdos, flotantes o no, podrían continuar, sea en forma de excursiones etnográficas - evoco aquí Grazalema, Icod de los Vinos o Graus- o de amistades duraderas que se gestaron en algún congreso y que han continuado hasta el tiempo presente. Pero, por asociación, intuyo que el tiempo que se me ha concedido se ha agotado ya.

De todas formas, no quiero terminar estas palabras sin desear, en mi nombre y en el de mis compañeras y compañeros del ITA, Associació d’Antropologia, y del DAFITS, a quienes en este momento represento, una feliz estancia en Tarragona y que el XIII Congreso de Antropología de la FAAEE os resulte lo más provechoso a todos los niveles posibles. Como anfitriones vuestros que vamos a ser estos cuatro próximos días os lo deseamos de todo corazón. 


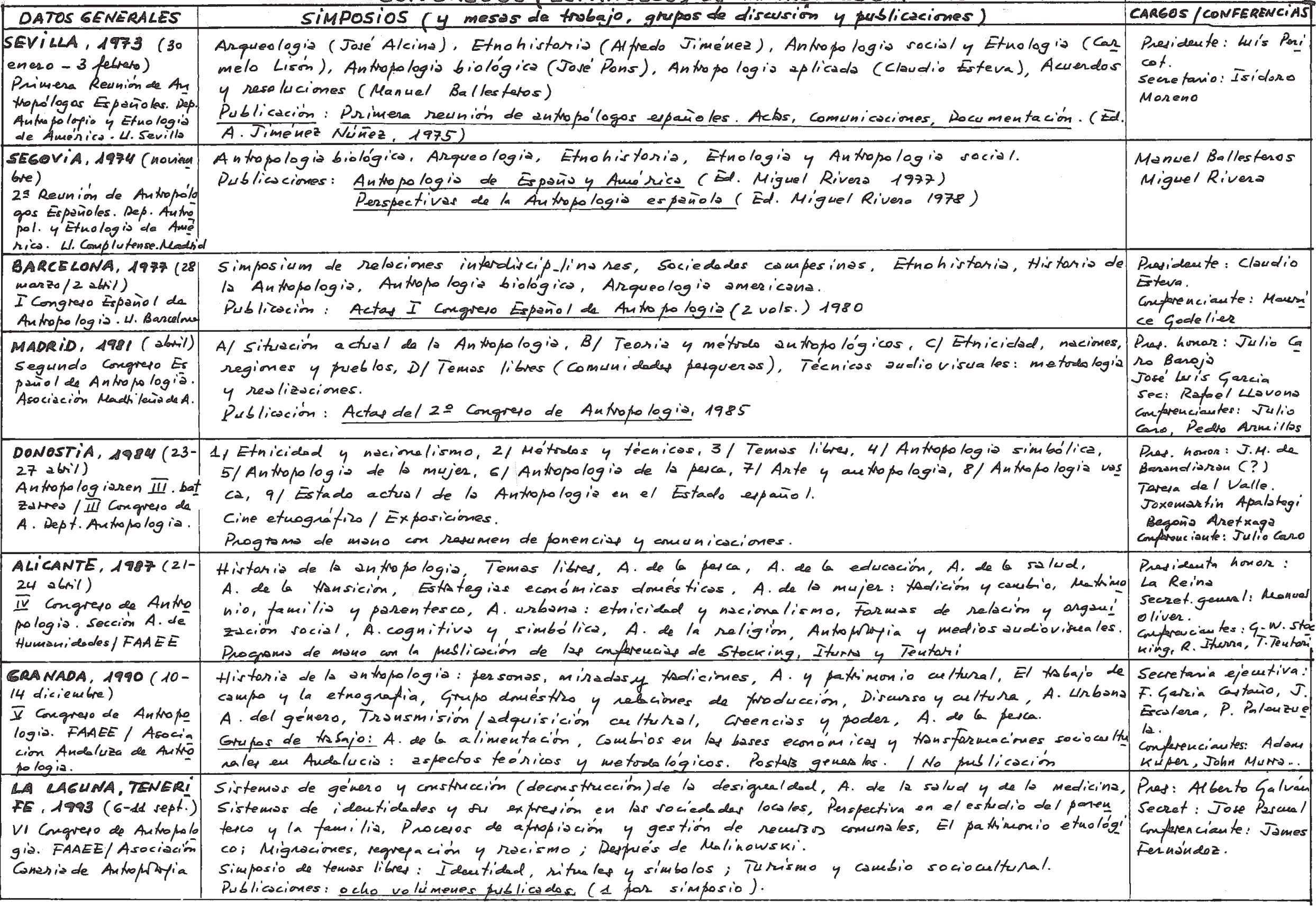




\section{DATOS GENERALES}

\section{ZARAGOZA, 1996}

$(16-20 \cdot \operatorname{sep} t$.

VII Congreso de An tituto Anguid. Ius theto Aragones de An

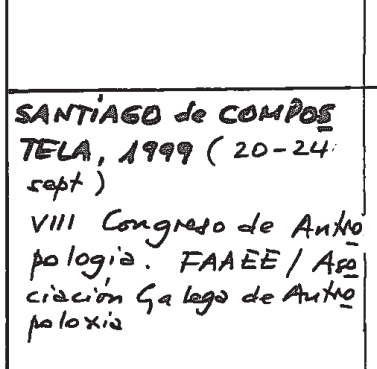

\section{BARCELONA, 2002}

(4-7 sest)

gè Congrés d'Autis pologia "Cu Hura i politica". Iustitut catala'd Autrop./FAAEE

\section{SEVILA, 2005 (19-22} tept.)

X Congraio de Au tropolo gie de 6 FAAEE" Caltes ras, pusaler y meacado" Atociación Andoluzo de Antropinyia / FAAEE
De la construcción de lo histaria 2 A faretro de la autropologia, Etuolinguirstica y areálisis del discusso, A. del tabajo; Reciprocided, cooperación y ongarización consinal: descle costa a nuestios dias; Familia, herencia y dorecho conseretudinasio. A. socidl de Ame'rica latina, Pro ceros migratorios y relaciones intersétricas, Epistemologia y mátorso

Grupos de discusión: A. de los edodos, A. en siturcimes de riesgo. A. de la a limentación. Patsi' monio etuológico y mureos. A. del thrismo. A. del gémers. Asociacionisuso y participación fo cial. Etica y autropologia: reflexión teórica. Etiza y autropologia : entre la teosia 4 la practic Publicaciones: ocho volímenes publiados (uno par simposio)

Globalización. frontars culturales y políticss y ciudadania. A. del género, A. de la peaca, A.Ju rídica. Nuevos movimientos religiosos: iglesias y "dectas", A. Y ecomonida politica; Patrimonio cultural 4 museologia : significados y contenido; A. mis allá de la academia: aplicaciones, conety' breciones frácticas $e$ intervoución vocial.

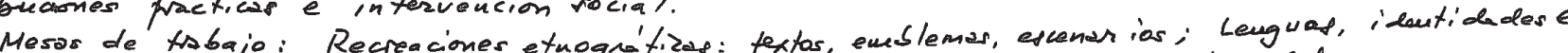

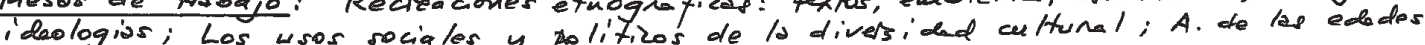

Publicaciones: 10 volímoner pus lizodo

1. El recurso de 6 reciprocidad, 2 . Sociabilided, politica y proceros de identificación colectiva, 3 . Recre

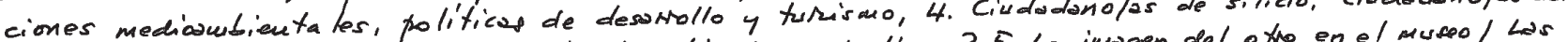

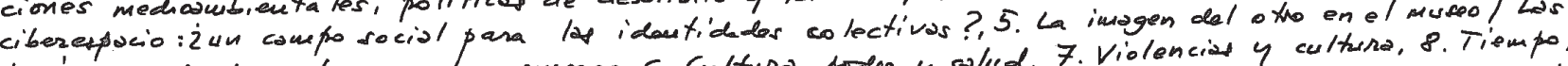
imagenes de los otros en los mureos, 6. Cultura, posear y salud. Fivioloncia to lixica educativas. de espacio y entarno en contaxtos urbanos, 9. Multicuthrralided, inmigracion y folitica edicotivase a

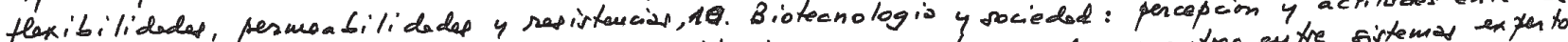
cioncio, dA. Usuerios, cliantes,

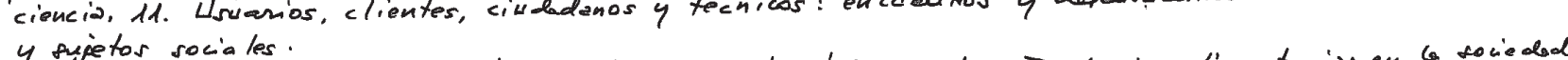

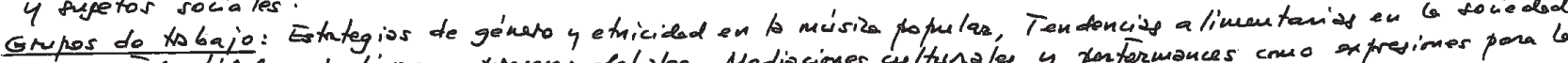

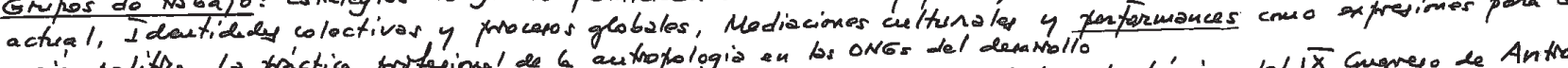

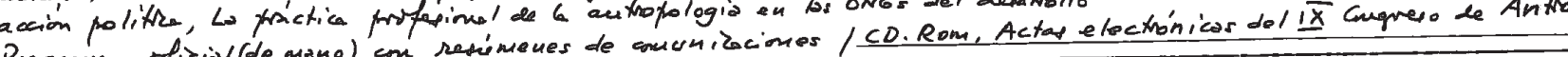
1. El encuentro al el patimonio cultural : concapciones teo'ricas y modalos de af 1 cacion, 2. La salud en uns socieded multicultural : desigualdad, merantilizacion y medicalizacions 3. A. de los media, 4. Pathinonio cultural: politizaciones y mercantilizacimes, 5. Cambibs aulfím

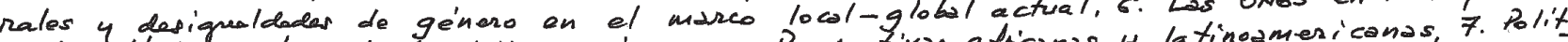
autroprológica dobre el deparbollo y viceversa. Penspectivas afticanas 4 latinoamericanas, a los culturat: iniciativas de has ablacines locales y sostenibilided, 9. Etnicidad en Latinoaméri

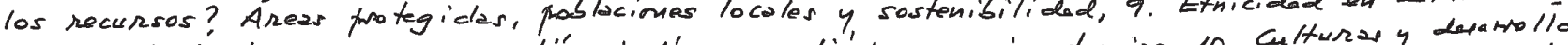
ca: movimientos sociales, cuestión indigena 4 diasporas migratorias, 10. Culturas y demas de en el marco de la globalización cafitalista, 11. Las politicas de lo momorid en los sistamided, poder mocrátros: Poder, cultura y mescado, 12. Autropologia Feminista $y / 0$ del Género. Legitimided poder y usos politiros.

Yesas do trbajo: Cultura andaluza, antropologia y globalización. I dentidades culturales, praler

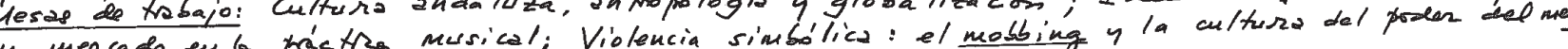
cads; Cutturas de portivas y mencador locales 4 globales

Publicaciones: 12 volumes (uno pos simposio)
Presidencie : Joan Josep Pujados. Carmen Gallego secretario: Pablo Pa lenzuelo

Prasidancia carsité Ro ingez cumps. In Rodiguer camptos, I doro Moreno.

Secret: Nieves thewer conterenciautes: Jomes Fenciando Z. Terance Tur Praridencin horer: Clas Pre verena stolche Pres: Verana sorola Isidoro Mronono Manue Secretanio:

Delgado ion tes: Roger Teanette Edwasds Edwa deanchoti' $M$. Carmeir da cunha, Jooep Ramón Labera.

Presidarter: Joos Miguel

dero Moreno.

Secretario: Tusan Agud conferenciante : Rosolfo staven.hagen orgaciza dor: Joaqu Bastra. Bruno Latour. 


\begin{tabular}{|c|c|c|}
\hline 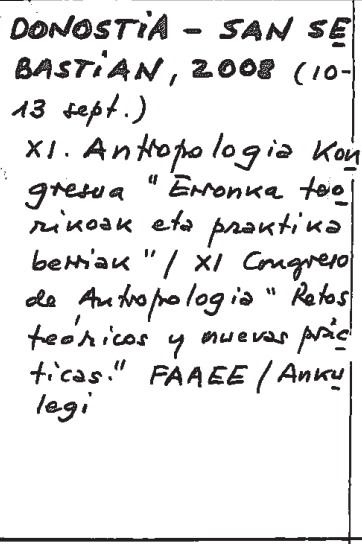 & 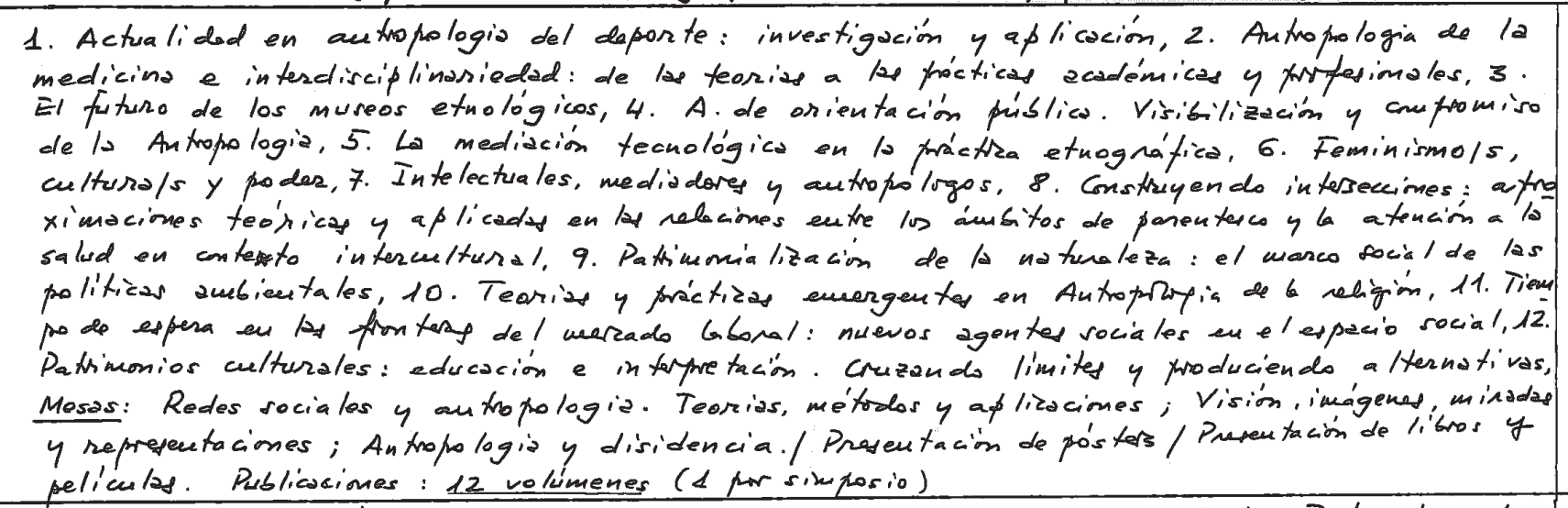 & $\begin{array}{l}\text { Presidencia: Teresa } \\
\text { del Valle, Tose' Mi' } \\
\text { guel (Txemi) Apá- } \\
\text { laza. } \\
\text { Secretaria. Carmen } \\
\text { Diez Mintegui }\end{array}$ \\
\hline 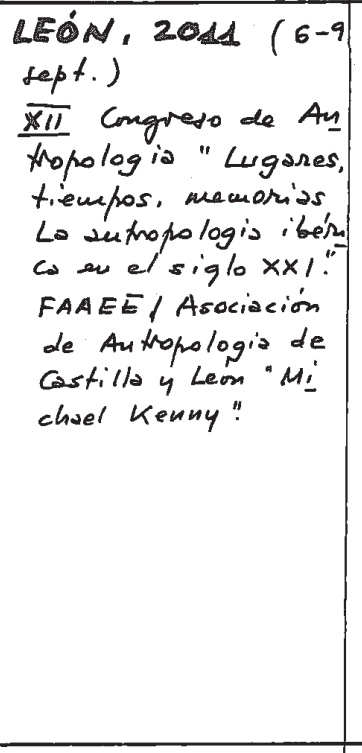 & 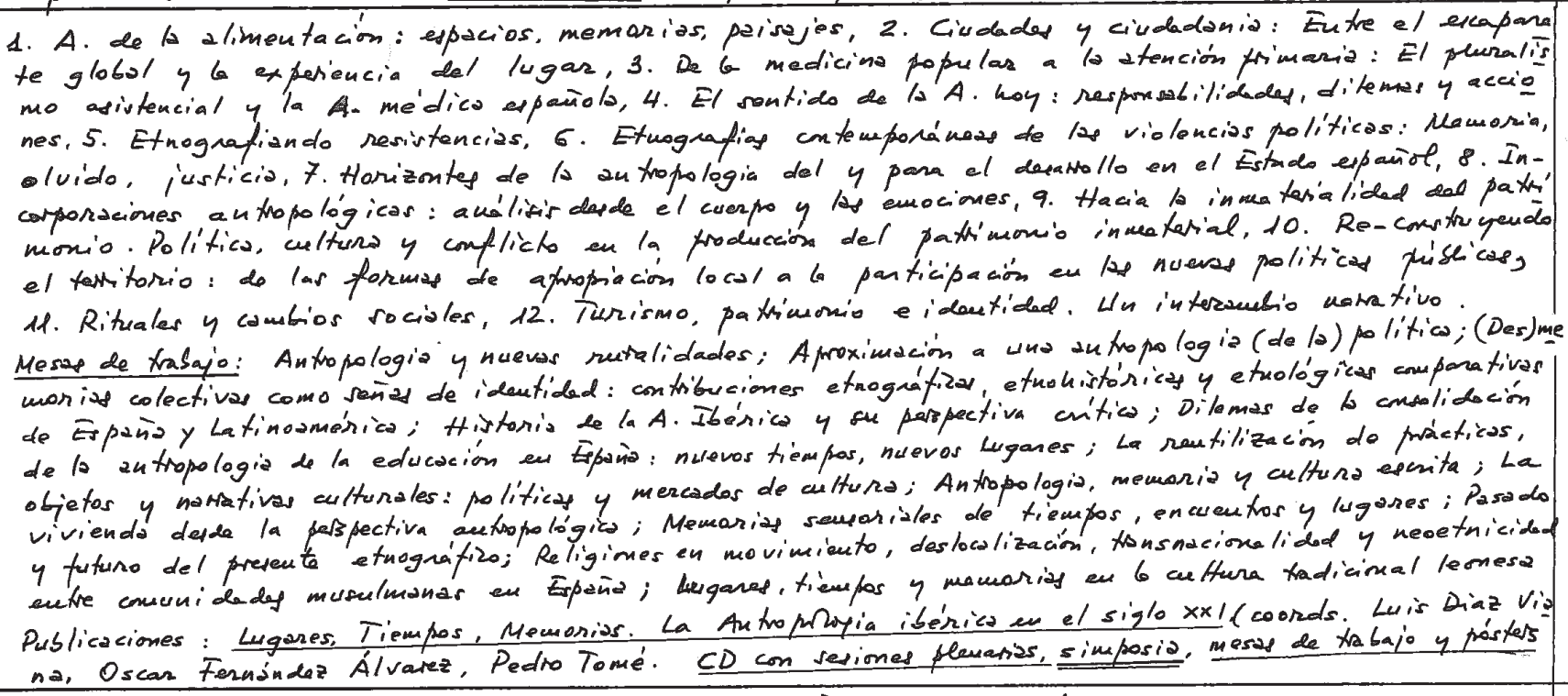 & 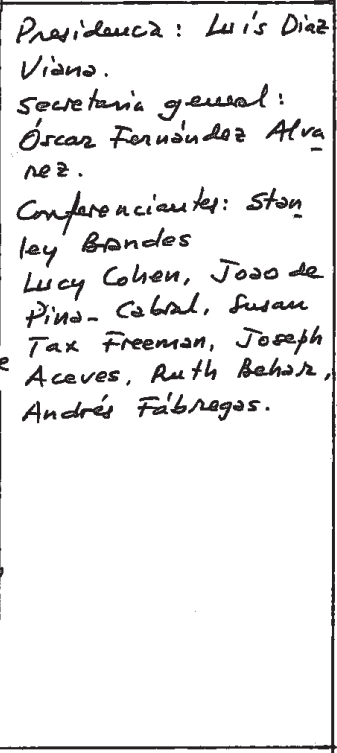 \\
\hline $\begin{array}{l}\text { TARRA GONA, } 2014 \\
\text { (2-5 sept) } \\
\text { XIII congràs d'Autio } \\
\text { pologia / Congreso da } \\
\text { Autiopologis "Perife } \\
\text { rias, frontaras y diá } \\
\text { logos. FAA EE / L'ITA, } \\
\text { Associació d'Antropolo }\end{array}$ & 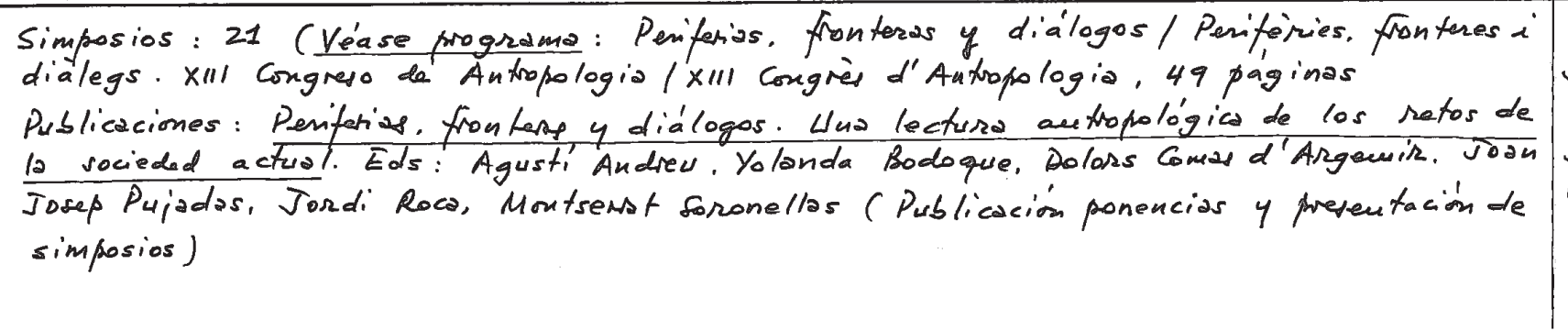 & $\begin{array}{l}\text { Conferenciautes: } \\
\text { Jorn F. Mira, Joan } \\
\text { Prat. Ramón Samsí, } \\
\text { Jrepa Cuco', Gary } \\
\text { W. MaDonogh. Vis } \\
\text { toria Ana Goddard. }\end{array}$ \\
\hline
\end{tabular}

